\title{
A Mathematical Model of Action Potential in Rat Atrial Cells
}

\author{
Na Zhao ${ }^{1}$, Yimen $\mathrm{Du}^{3}$, Kuanquan Wang ${ }^{1}$, Runnan $\mathrm{He}^{1}$, Henggui Zhang ${ }^{1,2,4}$, Qince $\mathrm{Li}^{1,4^{*}}$ \\ ${ }^{1}$ Harbin Institute of Technology, Harbin, China \\ ${ }^{2}$ The University of Manchester, Manchester, UK \\ ${ }^{3}$ Wuhan Union Hospital, Wuhan, China \\ ${ }^{4}$ Peng Cheng Laboratory, Shenzhen, China
}

\begin{abstract}
Atrial fibrillation $(A F)$ is a common cardiac arrhythmia associated with cardiac morbidity and mortality. Though several computational models have been developed to investigate mechanisms of atrial fibrillation in many species, there is no such model for adult rat atrial cells. A biophysically detailed mathematical model of the action potential of the rabbit atrial cells was developed based on experimental data recorded from rat right atrial cells. Conductance of $I_{t o}$, $I_{K u r}, I_{K r}, I_{K s}, I_{K I}$ as well as the time constant of $I_{t o}$ activation $\left(\tau_{s}\right)$ were modified to fit I-V curve of potassium current. Conductance, voltage dependent activation and inactivation of $I_{C a L}$ were modified to fit $I-V$, activation and inactivation curves of $I_{C a L}$ current. I-V, activation and inactivation curves of $I_{N a}$ current were fitted similarly. The action potential from the computational model are comparable to the action potential $(A P)$ recorded from rat atrial cells. The resting membrane potential, action potential amplitude and $A P D_{50}$ are $-67.4 \mathrm{mV}, 80.7 \mathrm{mV}$ and $18 \mathrm{~ms}$, respectively. This study, for the first time, developed a computational model of action potentials of rat atrial cells. The model can be used to further explore pathological mechanisms of atrial fibrillation.
\end{abstract}

\section{Introduction}

Atrial fibrillation (AF) is the most common arrhythmia observed in patients [1-3], AF can be mainly classified into three types, including paroxysmal, persistent, or chronic AF. In order to design optimal treatment for each type of AF, a profound understanding of the underlying mechanisms is required. In vivo experiments are required to get a better understanding of the role of ion channel remodeling in AF. Practically, a more common method is to investigate the mechanisms of AF in vitro. However, in vivo and in vitro have several limitations despite insights of the mechanism underlying arrhythmogenesis can be provided from these approaches. For example, in vivo and in vitro studies, it is impractical to investigate the electrophysiological properties at different physical scales (from cellular level to organ level) in one experiment. The electrophysiological properties recorded form different experiments, such as path clamp and optical mapping, may be affected by gradually change in cell/tissue properties. Therefore, computer models are widely used in cardiac arrhythmia studies in basic as well as clinical researches [4-7].

In order to investigate the mechanisms of AF in rats, the basis is a detailed computational model of the action potential of the rabbit atrial cells. Although, in last few decades, a large number of computational model have been developed for different cardiac cells in different species [8-13], a mathematical model for the adult rat atrial myocyte is still lacking.

In this study, we developed the first mathematical model for adult rat atrial cells, based on experimental data. The parameters of sodium, calcium and potassium current were adjusted to fit the experimental data obtained from patch clamp. The simulation results demonstrate that I-V, activation and inactivation curves of calcium, sodium and potassium currents are consistent with experimental data from the rat atrial cells. Also, the profile of simulated AP is consistent with experimental data

\section{Methods}

The patch clamp data are provided by Du et al. Rat atrial myocytes were patch-clamped using the whole-cell technique at $20-23^{\circ} \mathrm{C}$.

The cell membrane of the rat atrial myocytes was mimicked as an electrical circuit. The action potential behavior in a rat atrial myocyte was calculated by the following ordinary differential equation (Eq. 1),

$$
\mathrm{C}_{m} \frac{d V}{d t}=-I_{i o n}+I_{s t i m}
$$

where $C_{m}$ is the cell capacitance, $V$ is the transmembrane voltage, $t$ is time, $I_{i o n}$ is the total transmembrane ionic current, and $I_{\text {stim }}$ is the stimulus current. 
The total transmembrane ionic current $\left(I_{t o t}\right)$ was calculated as the summation of the fast $\mathrm{Na}^{+}$current $\left(I_{N a}\right)$, the L-type $\mathrm{Ca}^{2+}$ current $\left(I_{C a L}\right)$, the transient outward $\mathrm{K}^{+}$ current $\left(I_{t o}\right)$, the rapidly activating $\mathrm{K}^{+}$current $\left(I_{K r}\right)$, the slow activating $\mathrm{K}^{+}$current $\left(I_{K s}\right)$, the inward-rectifier $\mathrm{K}^{+}$ current $\left(I_{K 1}\right)$, the ultra-rapid delayed rectifier outward $\mathrm{K}^{+}$ current $\left(I_{K u r}\right)$, the $\mathrm{Ca}^{2+}$-activated $\mathrm{Cl}^{-}$current $\left(I_{C l C a}\right)$, the $\mathrm{Na}^{+} / \mathrm{Ca}^{2+}$ exchanger current $\left(I_{N a C a}\right)$, the $\mathrm{Na}^{+} / \mathrm{K}^{+}$pump current $\left(I_{N a K}\right), \quad \mathrm{Na}^{+} / \mathrm{K}^{+}$pump current $\left(I_{N a K}\right)$, the sarcolemmal Ca pump current $\left(I_{p C a}\right)$ and the background current $\left(I_{b}\right)$ as shown in Eq.2.

$$
\begin{aligned}
I_{t o t}= & I_{N a}+I_{C a}+I_{t o}+I_{K r}+I_{K s}+I_{K 1}+I_{K u r} \\
& +I_{C l C a}+I_{C a N a}+I_{N a K}+I_{p C a}+I_{b}
\end{aligned} .
$$

The current model was based on the model of human atrial cell developed by Grandi et al in 2011 [9] which incorporated the ultra-rapid delayed rectifier outward $\mathrm{K}^{+}$ current $\left(I_{K u r}\right)$ developed by Maleckar et al in 2009 [10]. The formulas of $I_{t o}, I_{K r}, I_{K}$ and $I_{K I}$ in Grandi's model were replaced with those developed by Majumder et al in 2016 [11]. The formulas of fast $\mathrm{Na}^{+}$current in Grandi's model were replaced with those developed by ten Tusscher et al in 2004 [12]. In order to reproduce the action potential of adult rat atrial cells, parameters of potassium, sodium and calcium ionic channels were modified to fit the experimental data.

\section{Results}

\section{1. $\mathrm{K}^{+}$currents}

In our model, as the main repolarization component, potassium current $\left(I_{K}\right)$ is consist of the $I_{t o}, I_{K r}, I_{K s}, I_{K l}$, and $I_{\text {Kur }}$ as shown in Eq.3.

$$
I_{K}=I_{t o}+I_{K r}+I_{K s}+I_{K 1}+I_{K u r} .
$$

Although it has been reported that $I_{t o}$ has two components that can rapidly and slowly recover from inactivation ( $I_{t o, f}$ and $I_{t o, s}$ ), in adult rat atrial cells, only $I_{t o, f}$ were observed in several studies. Therefore, only $I_{t o, f}$ current was calculated in current model.

The total potassium current was fitted with voltage clamp experimental data in rat right atrial cells. During the voltage clamp, the voltage was hold at $-40 \mathrm{~ms}$ for $110 \mathrm{~ms}$ in the beginning and then clamped to a series of testing potential ranging from $-90 \mathrm{mV}$ to $40 \mathrm{mV}$ with a step of $10 \mathrm{mV}$ for $500 \mathrm{~ms}$.

The conductance of the transient outward $\mathrm{K}^{+}$current $\left(G_{t o}\right)$, rapidly activating $\mathrm{K}^{+}$current $\left(G_{K r}\right)$, slow activating $\mathrm{K}^{+}$current $\left(G_{K s}\right)$, inward-rectifier $\mathrm{K}^{+}$current $\left(G_{K l}\right)$, ultrarapid delayed rectifier outward $\mathrm{K}^{+}$current $\left(G_{K u r}\right)$ as well as time constant of $I_{t o}$ inactivation ( $\left.\tau_{y t o f}\right)$ were adjusted to fit the peak and tail total potassium current from experim-
Table 1. Values of parameters of potassium currents.

\begin{tabular}{lll}
\hline Parameters & Value & Unit \\
\hline$G_{t o}$ & 0.48 & $\mathrm{mS} / \mu \mathrm{F}$ \\
$G_{K u r}$ & 0.0363 & $\mathrm{mS} / \mu \mathrm{F}$ \\
$G_{K r}$ & 0.01135 & $\mathrm{mS} / \mu \mathrm{F}$ \\
$G_{K s}$ & 0.0866 & $\mathrm{mS} / \mu \mathrm{F}$ \\
$G_{K 1}$ & 7.48 & $\mathrm{mS} / \mu \mathrm{F}$ \\
\hline
\end{tabular}
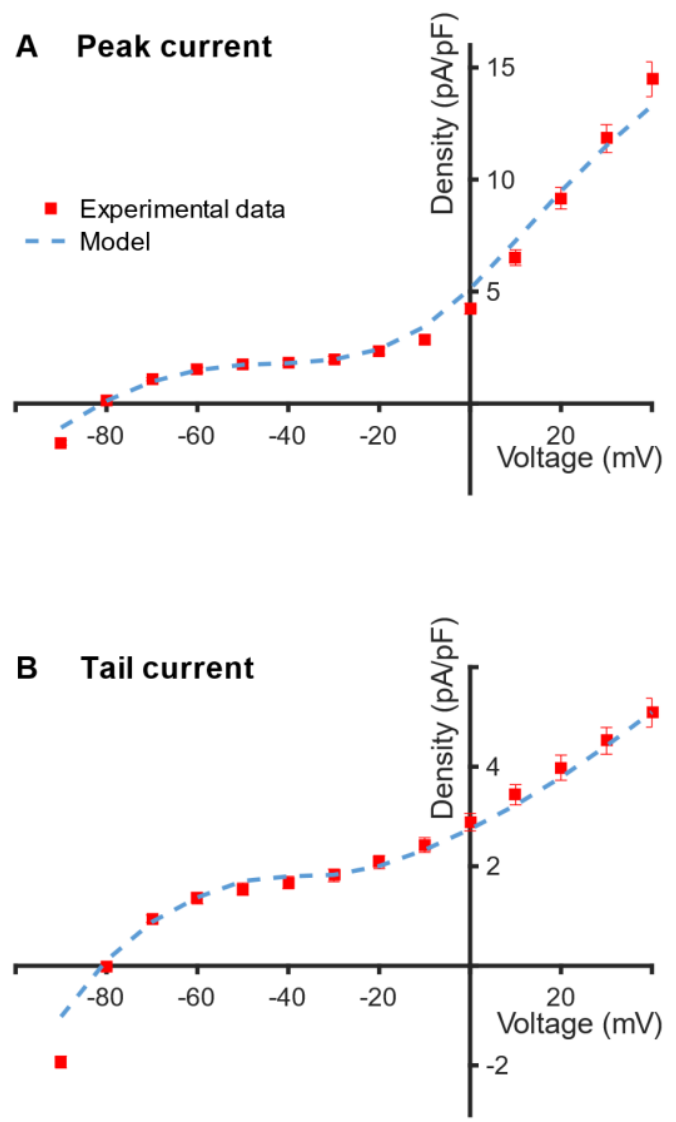

Figure 1. Data fitting of total potassium current.

ental data. The adjusted parameters and equations are listed in Tab. 1 and Eq. 4.

$$
\tau_{\text {ytof }}=0.35 \cdot \mathrm{e}^{-\left(\frac{V_{m}+70}{15}\right)^{2}+0.035}-15.64
$$

The fitting results of peak and tail total potassium current are shown in Figure 1A and 1B, respectively. The $\mathrm{I}-\mathrm{V}$ curves of peak and tail current had a similar profile. In the range from $-80 \mathrm{mV}$ to $-60 \mathrm{mV}$ and from $-20 \mathrm{mV}$ to $40 \mathrm{mV}$, both peak and tail currents increased significantly. However, in the range from $-60 \mathrm{mV}$ to $-20 \mathrm{mV}$, no significant change was observed in both curves. The simulation results were mainly consistent with experimental data in spite of a decline at $-90 \mathrm{mV}$. 

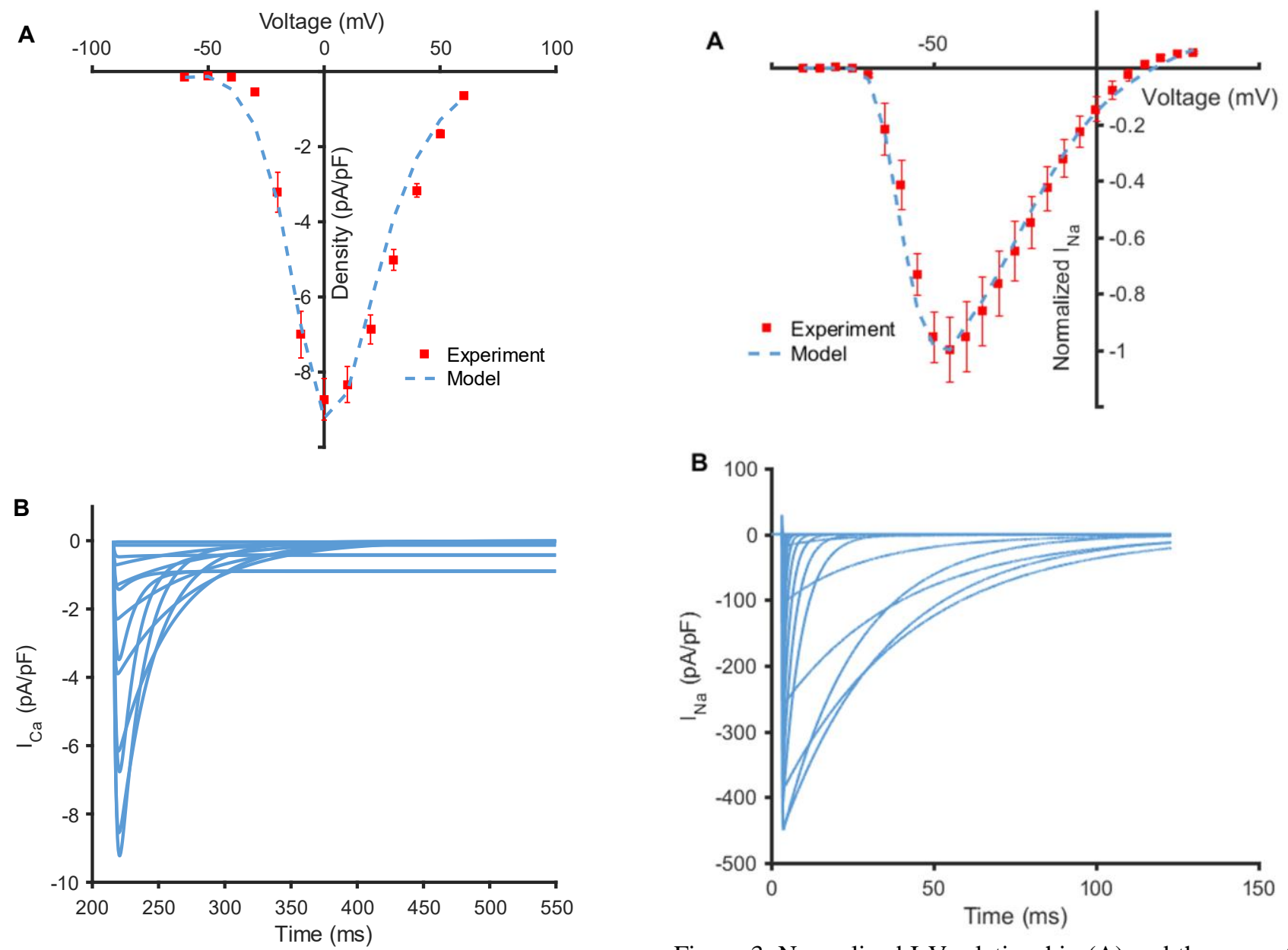

Figure 2. Reproduced I-V relationship (A) and the current traces $(\mathrm{B})$ of $\mathrm{I}_{\mathrm{CaL}}$ during voltage clamp.

\subsection{L-type $\mathrm{Ca}^{+}$current}

The permeability $\left(P_{C a}\right)$ and steady state voltagedependent activation $\left(d_{s s}\right)$, steady state voltage-dependent inactivation $\left(f_{s s}\right)$ and time constant of voltage-dependent inactivation $\left(\tau_{f}\right)$ of L-type $\mathrm{Ca}^{2+}$ current were modified to reproduce the I-V curve of $I_{C a L}$ measured in patch clamp.

The permeability was increased by 2.35 -folds to reproduce $I_{C a L}$ amplitude. The detailed modifications of gating variables of $I_{C a L}$ are shown in Eq.5-7.

$$
\begin{gathered}
d_{s s}=1-\frac{1}{1+e^{\left(\frac{V+8.85784}{6.60054}\right)}} \\
f_{s s}=\frac{1}{1+e^{\left(\frac{V+29.77913}{6.01471}\right)}} \\
\tau_{f}=\frac{14.1}{1+e^{\left(-\frac{(V+20.0)^{2}}{800}+0.2\right)}}
\end{gathered}
$$

Figure 3. Normalized I-V relationship (A) and the current traces $(B)$ of $\mathrm{I}_{\mathrm{Na}}$ during voltage clamp.

The fitting results of L-type $\mathrm{Ca}^{2+}$ current are shown in Figure 2. The simulated I-V curve of $I_{C a L}$ showed a bell shape with a peak value of $\sim 9.2 \mathrm{pA} / \mathrm{pF}$ at $0 \mathrm{mV}$ which is consistent with experimental data. In the simulation, the current density dropped a little faster than experimental recording at the range from $-50 \mathrm{mV}$ to $-20 \mathrm{mV}$ (Fig. 2A). Figure 2B demonstrated the simulated time traces of $I_{C a L}$ during voltage clamp. The results agree with the experimental recording as well (data not shown).

\subsection{Fast $\mathrm{Na}^{+}$current}

The formulas of $\mathrm{I}_{\mathrm{Na}}$ was based on the model developed by ten Tusscher et al. The steady state activation $\left(m_{s s}\right)$, time constant of activation $\left(\tau_{m}\right)$, steady state fast inactivation $\left(h_{s s}\right)$, time constant of fast activation $\left(\tau_{h}\right)$, steady state slow inactivation $\left(j_{s s}\right)$ and time constant of slow activation $\left(\tau_{j}\right)$ were modified to fit the experimental data and produce the upstroke of action potential.

The fitting results of fast $\mathrm{Na}^{+}$current are shown in Figure 3. The simulated I-V curve of $I_{N a}$ showed a bell 
shape with a peak value $\sim 450 \mathrm{pA} / \mathrm{pF}$ at $-45 \mathrm{mV}$ which is consistent with experimental data (Fig. 3A). Figure 3B demonstrated the simulated time traces of $I_{N a}$ during voltage clamp.

\subsection{Action potential}

The action potential was produced by applying a series of $1 \mathrm{~Hz}$ external stimuli with the amplitude $-80 \mathrm{pA} / \mathrm{pF}$ of and the duration of $1 \mathrm{~ms}$. The time trace of simulated AP is presented in Figure 4. The resting membrane potential, action potential amplitude and $\mathrm{APD}_{50}$ were measured as $67.4 \mathrm{mV}, 80.7 \mathrm{mV}$ and $18 \mathrm{~ms}$, respectively.

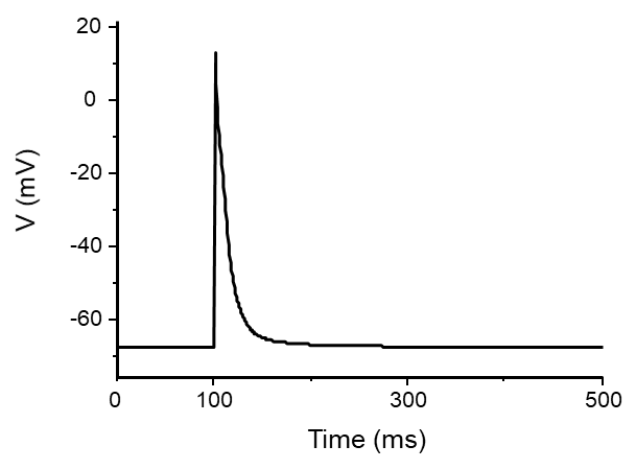

Figure 4. The simulated action potential at $1 \mathrm{~Hz}$.

\section{Conclusion}

In this study, we developed the first adult rat atrial computational model based on experimental data. The simulation results are consistent with experimental recordings. Development of such model is crucial since it would allow researchers to compare the results obtained in vivo/in vitro studies with the simulation results obtained in silico simulations.

\section{Acknowledgments}

The work is supported by the National Nature Science Foundation of China (NSFC) (No. 61601143 (to QL), 81770328 (to QL), 61572152 (to HZ), and 61571165 (to KW)), Heilongjiang and China Postdoctoral Science Foundation under Grant nos.2015M581448 (to QL).

\section{References}

[1] C. R. Wyndham. "Atrial fibrillation: the most common arrhythmia," Tex. Heart I. J., vol. 27, no. 3, pp. 257-267, Feb. 2000.

[2] M. C. Wijffels, C. J. Kirchhof, R. Dorland, J. Power, M. A. Allessie. "Electrical remodeling due to atrial fibrillation in chronically instrumented conscious goats - Roles of neurohumoral changes, ischemia, atrial stretch, and high rate of electrical activation" Circulation, vol. 96, no. 10, pp. 3710-3720, Nov. 1997.

[3] M. A. Allessie, "Atrial electrophysiologic remodeling: Another vicious circle?" J. Cardiovasc. Electr., vol. 9, no. 12, pp. 1378-1393, Dec. 1998.

[4] Z. L. Qu et al, "Scroll wave dynamics in a three-dimensional cardiac tissue model: roles of restitution, thickness, and fiber rotation," Biophys. J., vol. 78, no. 6, pp. 2761-2775, Jun. 2000.

[5] R. Majumder, A. R. Nayak, R. Pandit, "Scroll-wave dynamics in human cardiac tissue: lessons from a mathematical model with inhomogeneities and fiber architecture," PLoS One, vol. 6, no. 4, Apr. 2011, Art. no. e18052.

[6] P. M .Boyle et al, "Purkinje-mediated effects in the response of quiescent ventricles to defibrillation shocks," Ann. Biomed. Eng., vol. 38, no. 2, pp. 456-468, Feb. 2010.

[7] N. Trayanova, J. Eason, F. Aguel, "Computer simulations of cardiac defibrillation: a look inside the heart," Computing and Visualization in Science, vol. 4, no. 4, pp. 259-270, Jul. 2002.

[8] E. Grandi, F. S. Pasqualini, D. M. Bers, "A novel computational model of the human ventricular action potential and Ca transient," J. Mol. Cell. Cardiol., vol. 48, no. 1, pp. 112-121, Jan. 2010.

[9] E. Grandi et al, "Human atrial action potential and $\mathrm{Ca}^{2+}$ model: sinus rhythm and chronic atrial fibrillation," Circulation, vol. 109, no. 9, pp. 1055-1066, Oct. 2011.

[10] M. M. Maleckar et al, " $\mathrm{K}^{+}$current changes account for the rate dependence of the action potential in the human atrial myocyte," Am. J. Physiol.-Heart C., vol. 297, no. 4, pp. H1398-H1410, Oct. 200p.

[11] R. Majumder et al, "A mathematical model of neonatal rat atrial monolayers with constitutively active acetylcholinemediated K+ current," PLoS Comput. Biol., vol. 12, no. 6, Jun. 2016, Art. no. e1004946.

[12] K. ten Tusscher et al, "A model for human ventricular tissue," Am. J. Physiol.-Heart C., vol. 286, no. 4, pp. H1573-H1589, Apr. 2004.

[13] H. Zhang et al, "Mathematical models of action potentials in the periphery and center of the rabbit sinoatrial node," Am. J. Physiol.-Heart C., vol. 279, no. 1, pp. H397-H421, Jul. 2000.

Address for correspondence:

Qince Li

Xinjishu Building 901,

Harbin Institute of Technology

Xidazhi Street, Nangang District,

Harbin,

China

qinceli@hit.edu.cn 